\title{
BMJ Open Cross-sectional study on influence of the family environment on the lifetime non- medical use of prescription drugs among Chinese adolescents in Guangdong: an analysis of sex differences
}

Wanxin Wang, ${ }^{1}$ Min Luo, ${ }^{1}$ Chuhao Xi, ${ }^{1}$ Yiling Lei, ${ }^{1}$ Siyuan Pan, ${ }^{1}$ Xue Gao, ${ }^{2}$ Yan Xu, ${ }^{2}$ Guoliang Huang, ${ }^{2}$ Xueqing Deng, ${ }^{1}$ Lan Guo, ${ }^{1}$ CiYong Lu ${ }^{\oplus 1}$

To cite: Wang W, Luo M, $\mathrm{Xi}$ C, et al. Cross-sectional study on influence of the family environment on the lifetime non-medical use of prescription drugs among Chinese adolescents in Guangdong: an analysis of sex differences. BMJ Open 2019;9:e026758. doi:10.1136/ bmjopen-2018-026758

- Prepublication history for this paper is available online. To view these files, please visit the journal online (http://dx.doi. org/10.1136/bmjopen-2018026758).

WW and ML contributed equally.

Received 18 September 2018 Revised 28 May 2019 Accepted 3 June 2019

\section{Check for updates}

(c) Author(s) (or their employer(s)) 2019. Re-use permitted under CC BY-NC. No commercial re-use. See rights and permissions. Published by BMJ.

${ }^{1}$ Department of Medical Statistics and Epidemiology, School of Public Health, Sun Yat-sen University, Guangzhou, China

${ }^{2}$ Department of Drug Abuse Control, Center for ADR Monitoring of Guangdong, Guangzhou, China

\section{Correspondence to}

Dr. Lan Guo;

guolan3@mail.sysu.edu.cn and

Dr CiYong Lu;

luciyong@mail.sysu.edu.cn

\section{ABSTRACT}

Objectives This study aimed to assess if adolescents had used any prescription drugs non-medically, to explore the associations between the family environment and non-medical use of prescription drugs (NMUPD) and to investigate whether there are any sex differences in the aforementioned associations.

Design A population-based cross-sectional study. Setting A secondary analysis of the cross-sectional data collected from high school students in Guangdong who were sampled using a multistage, stratified-cluster, random-sampling method in the 2015 School-based Chinese Adolescents Health Survey.

Participants A total of 21774 students aged 12-20 years. Data analysis Multilevel logistic regression models were used to explore the univariable and multivariable relationship between family environment and NMUPD among adolescents. Adjusted ORs and corresponding $95 \% \mathrm{Cl}$ were calculated.

Outcome measures Questions regarding to adolescent' NMUPD (including sedative, opioid and stimulant) were surveyed in the study.

Results A total of $6.3 \%$ students reported lifetime NMUPD in this study. The most commonly used drugs were opioids (3.9\%), followed by sedatives $(3.2 \%)$ and stimulants (2.5\%). Multilevel analyses indicated that living arrangements, family economic status, parental relationships, parental education levels, monthly pocket money, parental drinking and drug problems were significantly correlated to the NMUPD among all students. Among boys, living arrangements, family economic status, maternal education levels, monthly pocket money, parental drinking and drug problems were significantly related to different types of NMUPD. The same factors were related to girls' NMUPD, except for maternal education levels. Parental relationships and paternal education levels were also associated with girls' NMUPD.

Conclusion The family environment exerts an important influence on adolescents' NMUPD. Interventions targeted at families are highly recommended considering the negative effects of NMUPD. In addition, the child's sex might be taken into consideration when developing and implementing preventive strategies.

\section{Strengths and limitations of this study}

- A large-scale, representative sample of adolescents living in Guangdong, China provided data for this cross-sectional study.

- Comprehensive dimensions of family environment were taken into consideration.

- Multilevel analyses were conducted on boys and girls separately to explore the sex difference.

- Data were collected based on subjective self-reported questionnaires, which may lead to information bias.

The sample was restricted to Guangdong province instead of the whole country.

\section{INTRODUCTION}

The non-medical use of prescription drugs (NMUPD) (eg, sedatives, tranquillisers and stimulants) is defined as using these drugs without a doctor's directions and for reasons other than the medication's intended purpose (such as 'to experiment' or 'to get high'). ${ }^{12}$ Over the last two decades, the NMUPD caused great concern due to sharp increases in drug use in the fields of psychiatry and neurology. ${ }^{3}$ According to the US report in the 2015 National Survey on Drug Use and Health, prescription drugs were second only to marijuana in the prevalence of illicit use. ${ }^{4}$ In Europe in 2015, the use of new psychoactive substances (narcotic or psychoactive substances that are not controlled by the United Nations drug conventions) seemed to be more common than the use of illicit drugs, such as cocaine and amphetamines. ${ }^{5}$ In China, a survey conducted in 2012 in Guangdong Province illustrated that the overall prevalence of the lifetime non-medical use of opioids and sedatives was $7.5 \%$ and $4.8 \%$, respectively. ${ }^{6}$ 
Adolescence is an important transition period from childhood to adulthood and it may be easily affected by the surrounding context. ${ }^{7}$ During this period, adolescents may be responsible for their own medication management and especially vulnerable to the negative effects of NMUPD for their still developing brains. ${ }^{8}$ Among different contexts, the family exerts a powerful influence on adolescent behaviours and expectations for the future. ${ }^{9}{ }^{10}$ Previous studies has indicated that the family environment was associated with adolescent NMUPD. ${ }^{11-16}$ For example, family economic status, ${ }^{12}$ family structures and relationships, ${ }^{13}$ parent-adolescent attachment, ${ }^{14}$ parental education levels ${ }^{15}$ and substance use $^{16}$ are related to adolescent drug abuse. It is well established that Chinese adolescents usually face high levels of stress in school, especially during high school and in preparation for the college entrance examination. ${ }^{17}$ Unsuitable habits or risk behaviours could be easily developed during this time ${ }^{18}$ if parents do not pay enough attention to adolescents. Additionally, due to the previous family planning policy in China, most families have only one child. ${ }^{19}$ Parents are one of the most important role models for adolescents. Thus, parental behaviours such as substance use may exert a deep influence on adolescent development. Previous research in China has also drawn similar conclusions. ${ }^{1}$ Therefore, it is reasonable to hypothesise that a positive family environment will serve as a buffer against adolescent NMUPD.

Generally, compared with girls, boys usually have higher probability of using prescription drugs without doctors' instruction. According to the US Youth Risk Behavior Surveillance (YRBS) 2015, male students had a higher prevalence of NMUPD than female ones. ${ }^{20}$ Similar situation also exist in China, according to previous studies. ${ }^{121}$ In addition, family could have different influences on boys and girls. For example, communication problems with their father significantly influenced boys' well-being yet girls were more sensitive to the communication problems with their mother. ${ }^{22}$ Moreover, girls can be more easily affected by their parents' behaviours such as problematic drinking and communication, compared with boys. ${ }^{22}$

The monitoring system of NMUPD is well conducted in developed regions, such as North America and Europe. In China, large-scale surveys on the family environment and NMUPD have been sporadic. A healthy surveillance system is warranted to be established. Therefore, this study was conducted to assess whether Chinese high school students had used prescription drugs non-medically, to determine the influences of the family environment on the NMUPD and to investigate whether there are any sex differences in the aforementioned associations.

\section{METHODS}

\section{Study design and participants}

The current study used the secondary cross-sectional data collected from high school students in Guangdong who were sampled in the 2015 School-based Chinese
Adolescents Health Survey. Multistage stratified cluster sampling was adopted to randomly sample school students in Guangdong Province. In stage 1, the province was categorised into three levels based on per capita gross domestic product (most, medium and least developed). Then, two cities were randomly chosen from each level. In stage 2, schools were categorised into three types: junior high (grades 7-9), senior high (grades 10-12) and vocational high schools (grades 10-12). In each city, six junior high, four senior high and two vocational high schools were randomly selected, depending on their locations (urban or suburban). In stage 3, two classes were randomly chosen from each grade in the selected schools (figure 1). All eligible students within the class were investigated. A total of 21780 students were invited to participate in this study and $21774(99.97 \%)$ of these students provided usable information. The final sample included 10297 (47.3\%) boys and $11010(50.6 \%)$ girls. The students' ages ranged from 12 to 20 years old, with the mean age of $15.4( \pm 1.85)$ years old. Most of the students $(98.6 \%)$ in this study are Han nationality. Students were required to finish the self-report questionnaire anonymously in classrooms in the absence of teachers to avoid possible bias. The survey was conducted under the supervision of well-trained medical graduate students. Before the survey, participants were informed about the purpose and procedure of the study. In addition, they were told that participation was voluntary.

\section{Patient and public involvement}

No patients or public were involved in the development of the research question, study design or data interpretation in this study.

\section{Measures}

Dependent variables

Lifetime NMUPD (including opioids, sedatives, stimulants and the non-medical use of any of these drugs) was measured by asking students the following question: 'have you ever taken the following medications not to treat sickness but just for fun or the feeling caused by the medication without a doctor's prescription (responses were coded as $1=y e s$ and $0=$ no)?'. Opioids included compound cough syrup with codeine, compound licorice tablets, tramadol hydrochloride and diphenoxylate. Stimulants included paracetamol caffeine aspirin powder. Sedatives included compound aminopyrine phenacetin tablets (barbiturates), diazepam or triazolam (benzodiazepines), phenobarbital and scopolamine hydrobromide tablets (barbiturates). All the drugs mentioned above were listed in the questionnaire for participants to choose. The list was generated based on to the report of Guangdong Food and Drug Administration, previous articles, ${ }^{21} 23$ advises from experts in substance misuse and paediatricians. The chosen drugs were reported to be easily obtained or widely misused by previous surveys.

\section{Family environment and sociodemographic factors}

Living arrangements were assessed by asking students with whom they live (with two biological parents, with one 


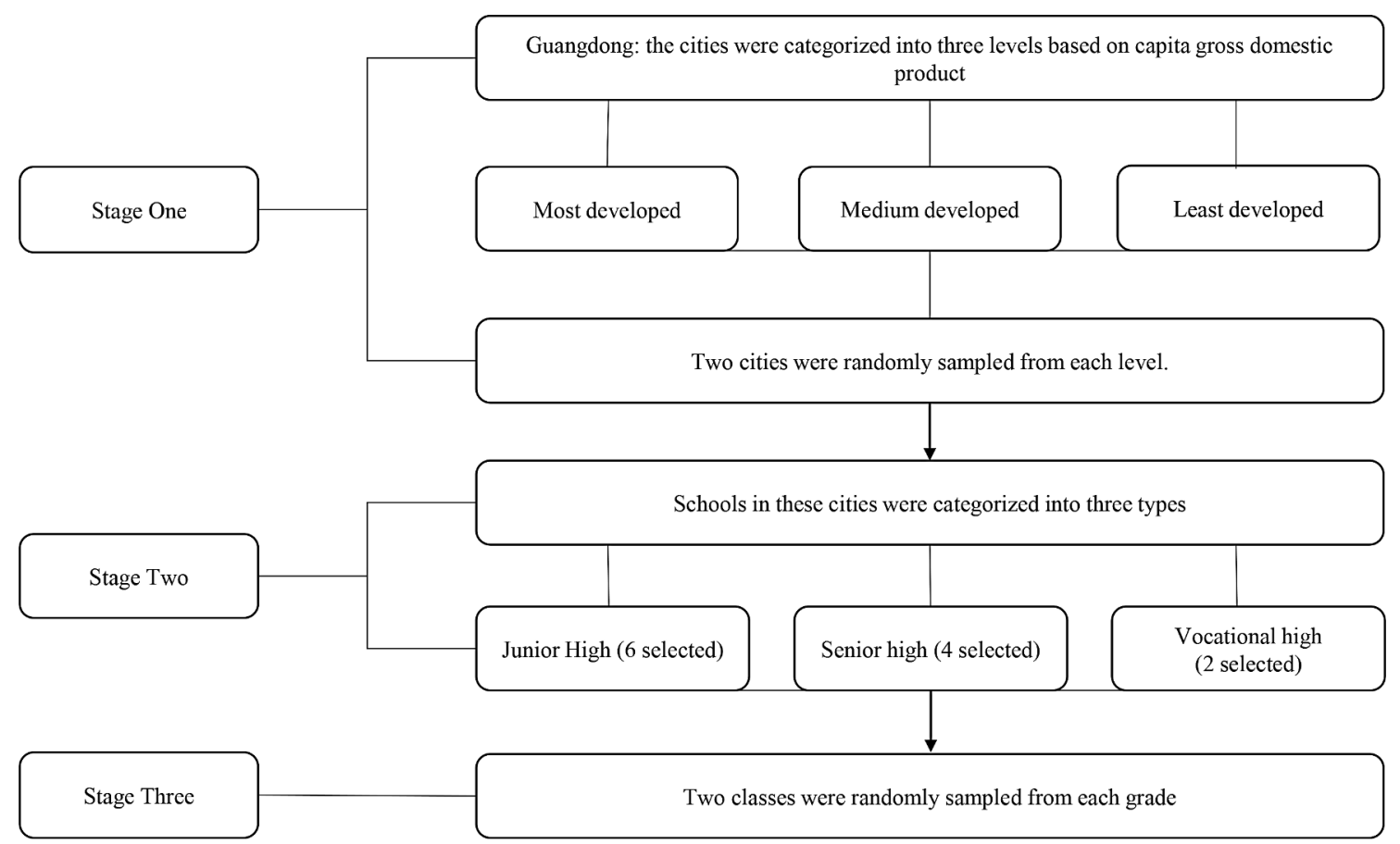

Figure 1 Flowchart of the sampling procedure.

single parent, or with relatives other than parents). Family economic status was measured by asking students about their perceptions of their family's current economic level (ranging from below average to above average). Pocket money was measured by asking students about the amount of pocket money they have per month $(<200 ¥, 200-399 ¥$ and $>400 ¥$, which equal to $<25 €, 25-50 €$ and $>50 €)$. Parental marital status was measured by asking students whether their parents' relationships were harmonious, conflicting, apart or divorced, or others (eg, parent had passed away). Parental education level was assessed by asking students if either of their parents had received a high level of education (university and higher). Parental smoking and drinking patterns were assessed by asking students whether their father or mother ever smoked more than once a week or had been drunk in the last 12 months. Parental drug use was assessed by asking whether their parents ever use the mentioned prescription drugs without any medical intentions. Other sociodemographic variables included sex $(1=$ male, $2=$ female $)$, nationality ( $1=$ Han nationality, $0=$ other nationality) and age.

\section{Statistical analysis}

All data were entered by two investigators using Epidata V.3.1. Statistical analyses were conducted using SPSS V.22.0. Descriptive analyses were used to describe demographics, family related characteristics and the prevalence of the NMUPD across sex. To assess any differential relationships by sex, analyses were conducted separately for boys and girls. All variables that were significant at a 0.25 level in the univariate analysis ${ }^{24}$ or widely reported to be associated with family dimensions were further submitted to multivariate analysis to identify independent risk factors for the NMUPD. Considering this study was a complex sampling design using multistage sampling, students were grouped into schools and might not be independent, therefore multilevel logistic regression models were fitted in which schools were treated as clusters. We used the procedure 'generalised estimated equation' in SPSS to perform multilevel logistic regression models. The associations between influential factors and dependent variables were measured by ORs and 95\% CI and all the multivariate analysis were adjusted for demographic characteristics and school cluster. Statistical significance was evaluated at the 0.05 level using two-sided tests.

\section{RESULTS \\ Sample characteristics and prevalence stratified by sex and NMUPD}

Basic demographic information across sex is illustrated in table 1 . The results showed that family environment and NMUPD situation among adolescent were different between boys and girls. The proportions of students who reported non-medical use of sedatives, opioids, stimulants and any of these drugs were $3.2 \%, 3.9 \%, 2.5 \%$ and $6.3 \%$, respectively. Furthermore, the overall prevalence of NMUPD among boys and girls is summarised, respectively. Among boys, the lifetime prevalence of the non-medical use of sedatives, opioids, stimulants and any of these drugs was $3.2 \%, 4.6 \%, 3.1 \%$ and $7.1 \%$, respectively. Among girls, the lifetime prevalence of the non-medical use of sedatives, opioids, stimulants and any of these drugs was $3.1 \%, 3.2 \%, 2.1 \%$ and $5.7 \%$, respectively. 
Table 1 Baseline characteristic across sex

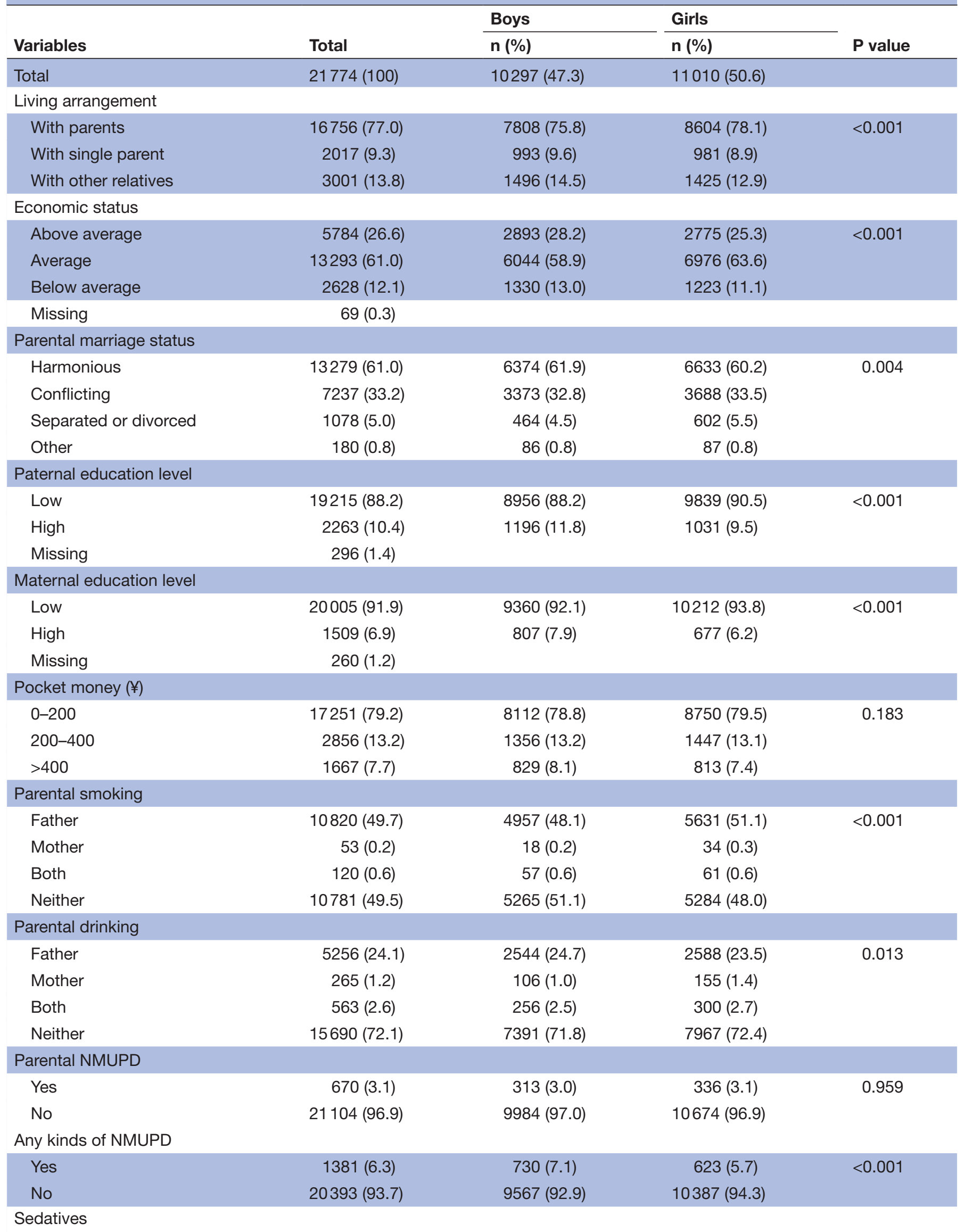


Table 1 Continued

\begin{tabular}{|c|c|c|c|c|}
\hline \multirow[b]{2}{*}{ Variables } & \multirow[b]{2}{*}{ Total } & \multirow{2}{*}{$\begin{array}{l}\text { Boys } \\
n(\%)\end{array}$} & \multirow{2}{*}{$\begin{array}{l}\text { Girls } \\
\mathrm{n}(\%)\end{array}$} & \multirow[b]{2}{*}{$P$ value } \\
\hline & & & & \\
\hline Yes & $686(3.2)$ & 334 (3.2) & $336(3.1)$ & 0.432 \\
\hline No & 21088 (96.8) & 9963 (96.8) & 10674 (96.9) & \\
\hline \multicolumn{5}{|l|}{ Opioids } \\
\hline Yes & 842 (3.9) & 476 (4.6) & $350(3.2)$ & $<0.001$ \\
\hline No & 20932 (96.1) & 9821 (95.4) & $10660(96.8)$ & \\
\hline \multicolumn{5}{|l|}{ Stimulants } \\
\hline Yes & 555 (2.5) & 315 (3.1) & 228 (2.1) & $<0.001$ \\
\hline No & 21219 (97.5) & 9982 (96.9) & $10782(97.9)$ & \\
\hline
\end{tabular}

NMUPD, non- medical use of prescription drugs.

\section{Multilevel multivariate logistic regression analyses: all adolescents}

The results of the final logistic regression model of the NMUPD among all surveyed adolescents are shown in table 2. The risk factors of NMUPD included living with neither of their biological parents, poor familial economic status, conflicting parents, more monthly pocket money and parental substance use. For example, adolescents who came from low-income families had a higher probability of using sedatives (adjusted OR $(\mathrm{AOR})=1.52$, $95 \%$ CI 1.18 to 1.96 ), opioids (AOR $=1.31,95 \%$ CI 1.03 to 1.66 ), stimulants (AOR $=1.52,95 \% \mathrm{CI} 1.15$ to 2.00 ) and any of these drugs (AOR $=1.35,95 \%$ CI 1.11 to 1.63 ). In contrast, higher levels of parental education (beyond college) appeared as a protective variable of adolescents' misusing stimulants and any drugs surveyed $(\mathrm{OR}<1)$.

\section{Multilevel multivariate logistic regression analyses: boys}

The results of the final multilevel logistic regression model for different kinds of NMUPD among boys are shown in table 3. The risk factors of NMUPD included not living with parents, below-average family economic status, more monthly pocket money and parental substance use. Maternal education level was a protective factor of the non-medical use of stimulants (AOR $=0.56,95 \%$ CI 0.33 to $0.96)$ and any of the surveyed drugs (AOR $=0.54,95 \% \mathrm{CI}$ 0.37 to 0.77$)$.

\section{Multilevel multivariate logistic regression analyses: girls}

Table 3 demonstrates that age, living arrangements, family economic status, parent relationships, paternal education levels, monthly pocket money and parental substance use were significantly associated with different kinds of NMUPD among girls. Notably, girls with well-educated fathers had lower probabilities of using sedative ( $\mathrm{AOR}=0.49,95 \%$ CI 0.30 to 0.79 ), opioids $(\mathrm{AOR}=0.58$, $95 \%$ CI 0.37 to 0.91 ), stimulants (AOR $=0.14,95 \%$ CI 0.05 to 0.38 ) or any of the prescription drugs in the study $(\mathrm{AOR}=0.51,95 \%$ CI 0.35 to 0.72$)$.

\section{DISCUSSION}

This is the large-scale study aimed to investigate the influence of family environment on adolescents' NMUPD. This study found that NMUPD is prevalent among Chinese adolescents and the prevalence was higher for boys than girls. In addition, negative family environment such as incomplete family structure, unpleasant family relationship, low socioeconomic status and parental substance use were positively related to adolescents' NMUPD.

Approximately $6.3 \%$ of the students reported lifetime NMUPD, with $7.1 \%$ among boys and $5.7 \%$ among girls. The most common drugs used for non-medical purposes were opioids, at $\sim 3.9 \%$. These prevalence rates were lower than the results revealed in surveys from other countries. The 2015 YRBS reported that $16.8 \%$ of the students had taken prescription drugs without a doctor's prescription at least once during their lifetime. ${ }^{20}$ According to the 2015 monitoring the future national survey, $5.9 \%$ of the 12th graders had used sedatives and $18.3 \%$ had used any prescription drug without a doctor's prescription during lifetime. ${ }^{2}$ It was demonstrated that Asians had lower levels of prescription drug misuse and Chinese were less likely to report lifetime prescription drug misuse, compared with other ethnic subgroups. ${ }^{25}$ Furthermore, the variance across studies might be caused by the methodologies of the studies, the differences in the nature of the samples.

Moreover, the family environment had influences on adolescents' NMUPD through different domains, such as family structure, economic status, parental relationships and parents' behaviour. First, living in a singleparent family or living without their biological parents was positively associated with adolescents' NMUPD. It is consistent with prior studies which suggested that adolescents living with two biological parents were less likely to report different kinds of NMUPD, ${ }^{13}$ providing a $32 \%$ reduction in the odds of NMUPD. ${ }^{26}$ Adolescents who lived with their biological parents can be more bonded and connected with their parents, ${ }^{27}$ and better parentchild attachment has been proven as a protective factor of adolescents' substance misuse. ${ }^{28}$ Second, similar with 
Table 2 Adjusted OR (AOR) and 95\% Cls of lifetime NMUPD among all adolescents

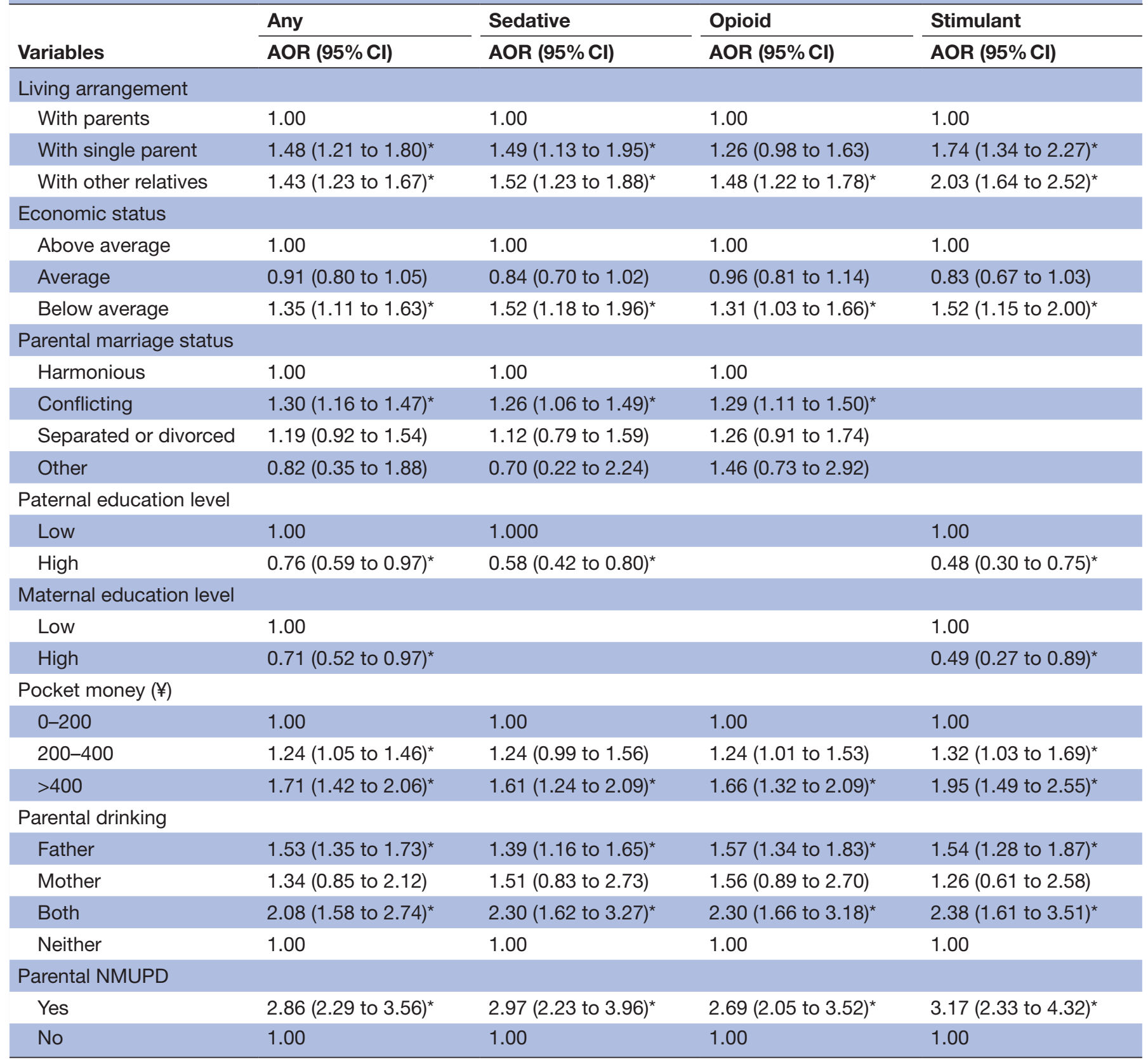

Models are adjusted for sex, age, nationality and school clusters.

${ }^{*} \mathrm{P}<0.05$.

NMUPD, non-medical use of prescription drugs.

previous studies, ${ }^{21} 29$ this study found that conflicting parental relationships were related to the increase risk of adolescents' NMUPD. A possible explanation is that parental conflict is one of the predictive factors of poor parenting, such as low monitoring, high hostility and bad discipline, which are further related to more substance use. ${ }^{30}$ Contrarily, positive family processes, such as close connections between family members, will lead to better parental monitoring, ${ }^{27}$ and better monitoring could reduce the level of prescription drugs misuse. ${ }^{31}$

Additionally, this study gave information about relationship between familial economic status and adolescents'
NMUPD. Adolescents with more pocket money were more likely to engage in the NMUPD and this effect increased with higher amounts of money. These results are consistent with those of a prior study showing that adolescents with more pocket money might be more likely to use prescription drugs non-medically. ${ }^{21}$ However, the present study indicated negative association between family economic status and the NMUPD among all adolescents. Similarly, previous investigations revealed that compared with wealthy families, individuals from low-income ones were more likely to use opioids, tobacco and cannabis. ${ }^{32} 33$ One explanation offered to such association 


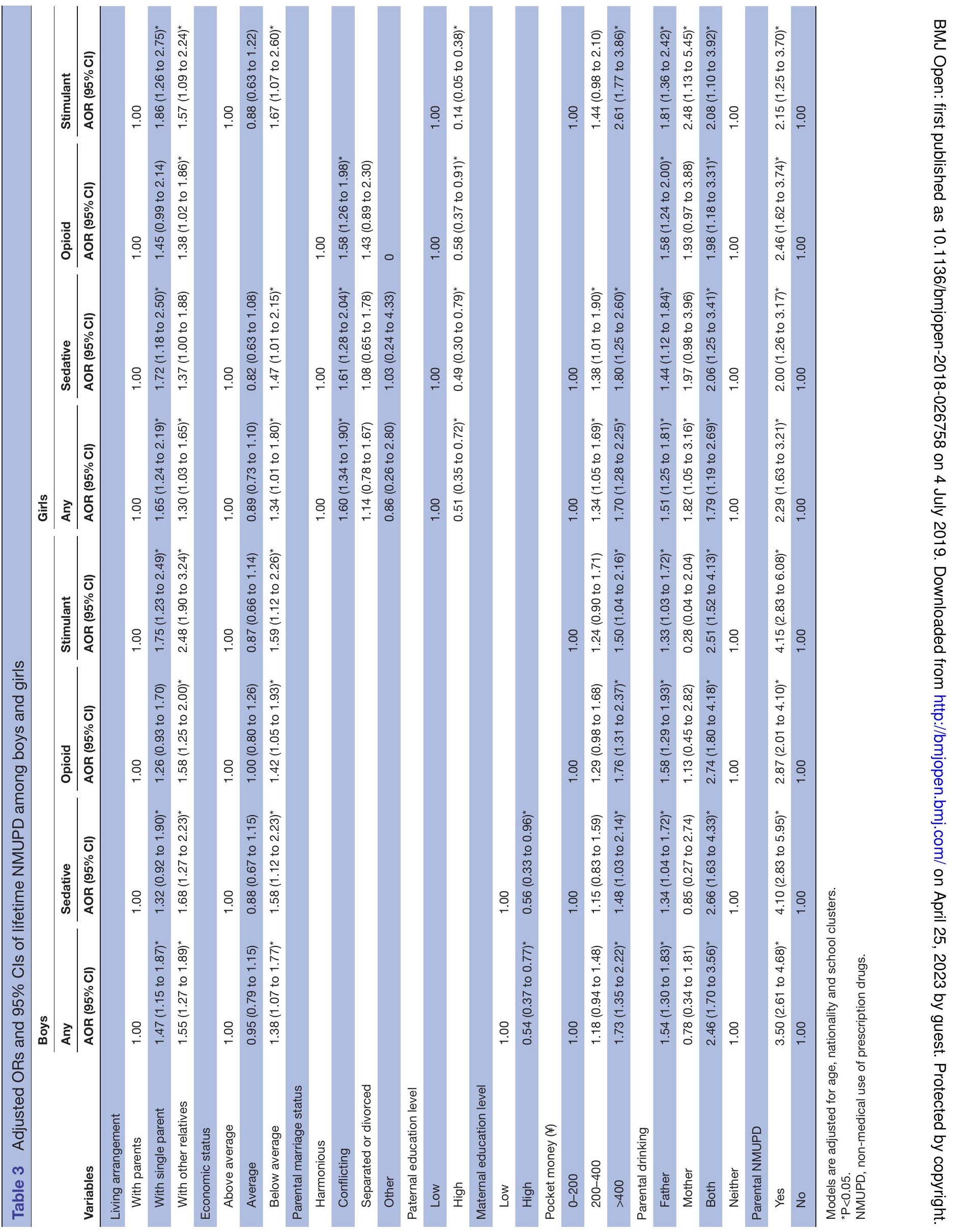


is that adolescents from low-income families may have less access to proper medical attention or guidance on using drugs. In addition, family economic hardship may influence young people's substance use by causing parents' emotional distress, which subsequently cause parental conflict and poor parenting style. ${ }^{30}$

In this study, parental substance use was significantly related to adolescents' NMUPD. Adolescents had higher probability of NMUPD if their parents (especially their fathers) had been drunk in the last 12 months or had ever used prescription drugs without medical intentions. Previous studies have also indicated that parental substance use was a risk factor for adolescents' substance use. ${ }^{134}$ Parental substances misuse may provide an unclear guidance and give adolescents a wrong idea that this behaviour is acceptable. ${ }^{35}$ Thus, adolescents may adopt the same behaviours. ${ }^{36}$ Evidence showed that parental disapproval of substance use was negatively related with adolescents' NMUPD ${ }^{37}$ Furthermore, parents' NMUPD could facilitate adolescents' access to those drugs. Previous studies have shown that family was one of the most common sources for adolescents' access to medications,${ }^{38}$ and this availability increases adolescents' chances of using these drugs. ${ }^{39}$

The stratification analyses in this study demonstrated that family conflict was related to a higher probability of the NMUPD among girls but not boys. Evidence suggests that girls are more emotionally sensitive than boys when it comes to dealing with stress or other negative situation, ${ }^{40}$ so they might be more vulnerable to their parents' and family relationships. Moreover, the results showed that girls were more affected by their fathers' education levels while boys were more affected by their mothers' education levels, indicating that parents' genders have different impacts on boys and girls. According to a previous study, father-daughter relationships were potentially related to dealing with psychosocial stress among girls, ${ }^{41}$ indicating that fathers may have a more profound influence on their daughter's behaviour. In addition, in this study, except for fathers' drinking habits, girls were more likely than boys to be affected by their mothers' drinking problems. Previous studies have drawn the same conclusions. ${ }^{35}$ In China, females usually drink and smoke less than males. Study has showed that teenage girls would feel more comfortable to communicate with their mothers about substance use. ${ }^{42}$ Therefore, as teenage girls' first role model, mothers' influence might be unique when they have problems with substance use.

\section{Strengths and limitations}

Several limitations of the study should be noted. First, this study only investigated students who were in school, but not those who dropped out of school or did not attend school on the day that the survey was conducted. Therefore, this sample may under-represent the true level of NMUPD. Second, it was a cross-sectional study; thus, the associations cannot be construed as causal. Third, the self-report questionnaire might introduce information bias like recall bias and dishonesty about drug use, although such method is commonly used and quality control was conducted to the best of our ability. Fourth, only lifetime NMUPD was assessed in this study. Recent (1year) and current (1 month) use will be considered in our future study. What is more, this study was only conducted in Guangdong province, which reduces the generalisability. Lastly, although NMUPD may be correlated with other substance use, in this study we did not collect information about other substance use. Other substance use (eg, smoking, drinking) will be included in our future study.

Despite these limitations, there are some strengths of this study. It was conducted based on a large-scale sample of adolescents in Guangdong Province. Economic difference across the whole province was taken into consideration during sampling procedure, which strengthen the representative of the sample. Furthermore, the influence of the family environment was comprehensively discussed from different dimensions, such as family socioeconomic status and parental behaviours. Third, different influences of the family environment on NMUPD across sex were explored separately in this study, which enable parents and government to address such problem differently based on the sex of adolescents.

\section{CONCLUSION}

This study explored the prevalence of adolescents' NMUPD and the influence of the family environment. The findings suggested that a negative family environment was highly related to adolescents' NMUPD. First, growing up with both biological parents is very important for adolescents. It would be better for adolescents if parents are more involved in children's lives, especially when they are divorced or when one of the biological parents has passed away. Second, the study indicated that it is important for parents to create a harmonious atmosphere for adolescents. If the family relationship is unpleasant, it would be better for parents to pay extra attention to their children's daily behaviour. Third, this study suggested that parental substance use has a negative influence on adolescents. We recommended parents to engage in healthy behaviours and provide clear guidance around drugs use when they are with their kids. Additionally, we suggested parents keeping track of their medicines so they would be aware if any of them are missing. These findings also serve as a reminder to parents that they should pay attention to the different dimensions of the family environment as they affect their children based on sex. Furthermore, a stricter regulation to limit the sale of prescription drugs to adolescents, effective interventions and policies enacted by the government to prevent the NMUPD are highly recommended. The child's sex plays a role in the association and we suggest that it should be taken into consideration when these interventions are made.

Acknowledgements The authors gratefully acknowledge the contribution of the Guangdong Education Bureau and its participating schools.

Contributors WW and ML participated in its design and coordination, performed the statistical analysis and drafted the manuscript. CX and YL participated in the 
design and interpretation of the data. SP participated in the design and coordination of the study and performed the measurement. XG, YX, GH and XD participated in data collection. $L G$ and $C L$ conceived of the study and participated in its design and coordination and helped to draft the manuscript. All authors read and approved the final manuscript.

Funding This study was supported by Centre for ADR monitoring of Guangdong (Grant number: GZSW11175FT4055).

Competing interests None declared.

Patient consent for publication Obtained.

Ethics approval The study received approval from the Sun Yat-sen University, School of Public Health Institutional Review Board. The research ethics number of approval is L2014076.

Provenance and peer review Not commissioned; externally peer reviewed.

Data sharing statement Data will be transferred if requested.

Open access This is an open access article distributed in accordance with the Creative Commons Attribution Non Commercial (CC BY-NC 4.0) license, which permits others to distribute, remix, adapt, build upon this work non-commercially, and license their derivative works on different terms, provided the original work is properly cited, appropriate credit is given, any changes made indicated, and the use is non-commercial. See: http://creativecommons.org/licenses/by-nc/4.0/.

\section{REFERENCES}

1. Guo L, Xu Y, Deng J, et al. Non-medical use of prescription pain relievers among high school students in China: a multilevel analysis. BMJ Open 2015:5:11.

2. Miech RA, Johnston LD, O'Malley PM, et al. Monitoring the Future national survey results on drug use, 1975-2015. Secondary school students. Ann Arbor: Institute for Social Research, The University of Michigan, 2016; Volume I.

3. Novak S, Calvin S, Glasheen C, et al. The Epidemiology and Treatment of Prescription Drug Disorders in the United States. 2011.

4. Quality CfBHSa. Key substance use and mental health indicators in the United States: Results from the 2015 National Survey on Drug Use and Health U.S. Department of Health and Human Services. 2016:Contract No.: SMA 16-4984.

5. Group E. ESPAD Report 2015: Results from the European School Survey Project on Alcohol and Other Drugs. Luxembourg, 2016.

6. Juan W, Jian-Xiong D, Lan G, et al. Non-medical use of psychoactive drugs in relation to suicide tendencies among Chinese adolescents. Addict Behav 2015;51:31-7.

7. Fine A, Mahler A, Steinberg L, et al. Individual in Context: The Role of Impulse Control on the Association between the Home, School, and Neighborhood Developmental Contexts and Adolescent Delinquency. $J$ Youth Adolesc 2017;46:1488-502.

8. Casey BJ, Getz S, Galvan A. The adolescent brain. Dev Rev 2008;28:62-77.

9. Johnson MK, Hitlin S. Family (Dis)Advantage and Life Course Expectations. Soc Forces 2017;95:997-1022.

10. Holliday SB, Edelen MO, Tucker JS. Family Functioning and Predictors of Runaway Behavior Among At-Risk Youth. Child Adolesc Social Work J 2017;34:247-58.

11. Nargiso JE, Ballard EL, Skeer MR. A systematic review of risk and protective factors associated with nonmedical use of prescription drugs among youth in the United States: a social ecological perspective. J Stud A/cohol Drugs 2015;76:5-20.

12. Ford JA. Nonmedical Prescription Drug Use Among Adolescents The Influence of Bonds to Family and School. Youth Soc 2009;40:336-52.

13. Young AM, Glover N, Havens JR. Nonmedical use of prescription medications among adolescents in the United States: a systematic review. J Adolesc Health 2012;51:6-17.

14. Gattamorta KA, Varela A, McCabe BE, et al. Psychiatric Symptoms, Parental Attachment, and Reasons for Use as Correlates of Heavy Substance Use Among Treatment-Seeking Hispanic Adolescents. Subst Use Misuse 2017;52:392-400.

15. Bachman JG, O'Malley PM, Johnston LD, et al. Racial/ethnic differences in the relationship between parental education and substance use among U.S. 8th-, 10th-, and 12th-grade students: findings from the Monitoring the Future project. J Stud Alcohol Drugs 2011;72:279-85

16. Xue $\mathrm{G}, \mathrm{Ci}$-yong $\mathrm{L}$, Jian-xiong $\mathrm{D}$, et al. The influence of family factors and personal cognitive on non-medical drug-use among high school students. Chinese Journal of Drug Abuse Prevention and Treatment 2015;21:315-8.

17. Wang RK, Ma X. LIX, et al. Psychological stress and mental health in seniors at high school. Int J Pathol Clin Med 2013;33:4.

18. Liu Y, Lu Z, Zh L. Chinese high school students' academic stress and depressive symptoms: gender and school climate as moderators. Stress Health 2012;28:340-6.

19. Hesketh T, Lu L, Xing ZW. The effect of China's one-child family policy after 25 years. N Engl J Med 2005;353:1171-6.

20. Kann L, McManus T, Harris WA, et al. Youth Risk Behavior Surveillance - United States. MMWR Surveill Summ 2016;2015.

21. Wang H, Deng J, Zhou X, et al. The nonmedical use of prescription medicines among high school students: a cross-sectional study in Southern China. Drug Alcohol Depend 2014;141:9-15.

22. Ohannessian CM. Parental Problem Drinking and Adolescent Psychological Problems: The Moderating Effect of Adolescent-Parent Communication. Youth Soc 2013;45:3-26.

23. Guo L, Xu Y, Deng J, et al. Association Between Nonmedical Use of Prescription Drugs and Suicidal Behavior Among Adolescents. JAMA Pediatr 2016;170:971-8.

24. Hosmer DWJ, Lemeshow S, Sturdivant RX. Applied Logistic Regression. 3rd edn: Wiley, 2013.

25. Watkins WC, Ford JA. Prescription drug misuse among AsianAmerican adults: results from a national survey. Subst Use Misuse 2011;46:1700-8.

26. Havens JR, Young AM, Havens CE. Nonmedical prescription drug use in a nationally representative sample of adolescents: evidence of greater use among rural adolescents. Arch Pediatr Adolesc Med 2011;165:250-5.

27. Fosco GM, Stormshak EA, Dishion TJ, et al. Family relationships and parental monitoring during middle school as predictors of early adolescent problem behavior. J Clin Child Adolesc Psychol 2012;41:202-13.

28. McLaughlin A, Campbell A, McColgan M. Adolescent Substance Use in the Context of the Family: A Qualitative Study of Young People's Views on Parent-Child Attachments, Parenting Style and Parental Substance Use. Subst Use Misuse 2016:51:1846-55.

29. Ljubotina D, Galić J, Jukić V. Prevalence and risk factors of substance use among urban adolescents: questionnaire study. Croat Med J 2004;45:88-98.

30. Martin MJ, Conger RD, Robins RW. Family stress processes and drug and alcohol use by Mexican American adolescents. Dev Psychol 2019;55:170-83.

31. Clark HK, Shamblen SR, Ringwalt CL, et al. Predicting high risk adolescents' substance use over time: the role of parental monitoring. J Prim Prev 2012;33(2-3):67-77.

32. Nakawaki B, Crano WD. Predicting adolescents' persistence, nonpersistence, and recent onset of nonmedical use of opioids and stimulants. Addict Behav 2012;37:716-21.

33. Charitonidi E, Studer J, Gaume J, et al. Socioeconomic status and substance use among Swiss young men: a population-based crosssectional study. BMC Public Health 2016;16:11.

34. Cranford JA, McCabe SE, Boyd CJ. Adolescents' nonmedical use and excessive medical use of prescription medications and the identification of substance use subgroups. Addict Behav 2013;38:2768-71.

35. Yule AM, Wilens TE, Martelon MK, et al. Does exposure to parental substance use disorders increase substance use disorder risk in offspring? A 5-year follow-up study. Am J Addict 2013;22:460-5.

36. Shorey RC, Fite PJ, Elkins SR, et al. The association between problematic parental substance use and adolescent substance use in an ethnically diverse sample of 9th and 10th graders. J Prim Prev 2013;34:381-93.

37. Su J, Supple AJ. Parental, peer, school, and neighborhood influences on adolescent substance use: direct and indirect effects and ethnic variations. J Ethn Subst Abuse 2014;13:227-46.

38. Schepis TS, Krishnan-Sarin S. Sources of prescriptions for misuse by adolescents: differences in sex, ethnicity, and severity of misuse in a population-based study. J Am Acad Child Adolesc Psychiatry 2009;48:828-36.

39. Collins D, Abadi MH, Johnson K, et al. Non-medical use of prescription drugs among youth in an Appalachian population: prevalence, predictors, and implications for prevention. J Drug Educ 2011;41:309-26.

40. WHO. Preventing suicide: A global imperative. Geneva WHO, 2014.

41. Byrd-Craven J, Auer BJ, Granger DA, et al. The father-daughter dance: the relationship between father-daughter relationship quality and daughters' stress response. J Fam Psychol 2012;26:87-94.

42. Miller-Day MA. Parent-Adolescent Communication about Alcohol, Tobacco, and Other Druguse. J Adolesc Res 2002;17:604-16. 